University of Nebraska - Lincoln

DigitalCommons@University of Nebraska - Lincoln

Faculty Publications from the Harold W. Manter Laboratory of Parasitology

2003

PHYLOGENETIC ANALYSIS OF THE METASTRONGYLOIDEA (NEMATODA: STRONGYLIDA) INFERRED FROM RIBOSOMAL RNA GENE SEQUENCES

\author{
Ramon A. Carreno \\ Ohio Wesleyan University \\ Steven A. Nadler \\ University of California - Davis, sanadler@ucdavis.edu
}

Follow this and additional works at: https://digitalcommons.unl.edu/parasitologyfacpubs

Part of the Parasitology Commons

\begin{abstract}
Carreno, Ramon A. and Nadler, Steven A., "PHYLOGENETIC ANALYSIS OF THE METASTRONGYLOIDEA (NEMATODA: STRONGYLIDA) INFERRED FROM RIBOSOMAL RNA GENE SEQUENCES" (2003). Faculty Publications from the Harold W. Manter Laboratory of Parasitology. 710.

https://digitalcommons.unl.edu/parasitologyfacpubs/710
\end{abstract}

This Article is brought to you for free and open access by the Parasitology, Harold W. Manter Laboratory of at DigitalCommons@University of Nebraska - Lincoln. It has been accepted for inclusion in Faculty Publications from the Harold W. Manter Laboratory of Parasitology by an authorized administrator of DigitalCommons@University of Nebraska - Lincoln. 


\title{
PHYLOGENETIC ANALYSIS OF THE METASTRONGYLOIDEA (NEMATODA: STRONGYLIDA) INFERRED FROM RIBOSOMAL RNA GENE SEQUENCES
}

\author{
Ramon A. Carreno* and Steven A. Nadler \\ Department of Nematology, University of California-Davis, Davis, California 95616. e-mail: racarren@owu.edu
}

\begin{abstract}
Phylogenetic relationships among nematodes of the strongylid superfamily Metastrongyloidea were analyzed using partial sequences from the large-subunit ribosomal RNA (LSU rRNA) and small-subunit ribosomal RNA (SSU rRNA) genes. Regions of nuclear ribosomal DNA (rDNA) were amplified by polymerase chain reaction, directly sequenced, aligned, and phylogenies inferred using maximum parsimony. Phylogenetic hypotheses inferred from the SSU rRNA gene supported the monophyly of representative taxa from each of the 7 currently accepted metastrongyloid families. Metastrongyloid taxa formed the sister group to representative trichostrongyloid sequences based on SSU data. Sequences from either the SSU or LSU RNA regions alone provided poor resolution for relationships within the Metastrongyloidea. However, a combined analysis using sequences from all rDNA regions yielded 3 equally parsimonious trees that represented the abursate Filaroididae as polyphyletic, Parafilaroides decorus as the sister species to the monophyletic Pseudaliidae, and a sister group relationship between Oslerus osleri and Metastrongylus salmi. Relationships among 3 members of the Crenosomatidae, and 1 representative of the Skrjabingylidae (Skrjabingylus chitwoodorum) were not resolved by these combined data. However, members of both these groups were consistently resolved as the sister group to the other metastrongyloid families. These relationships are inconsistent with traditional classifications of the Metastrongyloidea and existing hypotheses for their evolution.
\end{abstract}

The Metastrongyloidea consists of strongylid nematodes that are grouped together on the basis of site specificity of adults in mammals (primarily in the respiratory system), a reduced copulatory bursa, and heteroxenous life cycles (Anderson, 1978). Included in the superfamily are several species that elicit pathology in the bronchi, bronchioli, and lungs of their hosts (Testi and Pilleri, 1969; Stockdale, 1976; Bolt et al., 1994; Baker et al., 1995). Although adults of most metastrongyloid taxa are parasites of the respiratory system, other predilection sites for some metastrongyloid taxa have evolved, including the central nervous system and musculature of cervids (elaphostrongyline nematodes; Protostrongylidae), frontal sinuses of mustelids (Skrjabingylidae), and the circulatory system as represented by various species in the Angiostrongylidae and Pseudaliidae (Skrjabin et al., 1952; Anderson, 2000).

Most species for which life cycles have been demonstrated use gastropods as intermediate hosts. However, nongastropod intermediate hosts also exist, such as fishes in the life cycle of Parafilaroides decorus from pinnipeds (Dailey, 1970) and earthworms in the life cycle of Metastrongylus spp. in suids (Anderson, 2000). Thus, a wide variety of predilection sites, mammalian hosts, and life cycle strategies are known among the Metastrongyloidea.

Despite this diversity, few attempts have been made to study the phylogeny of the Metastrongyloidea. Traditional evolutionary hypotheses for this group have been based on limited information, speculative views on the phylogeny of nematodes based on assumptions of host-parasite coevolution, and different interpretations of the relative significance of anatomical features of the nematodes (Skrjabin, 1941, 1942; Dougherty, 1949b; Delyamure, 1955). Many of these views were expressed by Durette-Desset et al. (1994), who summarized the phylogeny of the metastrongyloids as a process involving life cycle modifications as a dominant evolutionary phenomenon, coupled

Received 30 December 2002; revised 14 May 2003; accepted 15 May 2003.

* Present address: Department of Zoology, Ohio Wesleyan University, Delaware, Ohio 43015. with the extensive use of intermediate and paratenic hosts and the invasion of numerous extraintestinal sites.

In contrast, many advances in phylogenetic reconstruction, including the use of molecular data, have made it possible to study the phylogeny of nematodes using additional methods that can complement morphological characters. In recent years, phylogenetic analyses of nematodes using small-subunit ribosomal RNA (SSU rRNA) sequences have produced interesting hypotheses that have refined our understanding of nematode evolution (Blaxter et al., 1998; Nadler and Hudspeth, 1998; Blaxter, 2001). SSU-based phylogenetic hypotheses have also revealed that the Strongylida are nested within the Rhabditida (Blaxter et al., 1998; Sudhaus and Fitch, 2001).

Despite these advances and recent progress in understanding the phylogeny of various strongylid groups within the superfamilies Trichostrongyloidea (e.g., Hoberg and Lichtenfels, 1994; Durette-Desset et al., 1999; Gouy de Bellocq et al., 2001) and Strongyloidea (e.g., Chilton et al., 1997; Hung et al., 1999), neither morphological nor molecular characters have been used to evaluate the phylogenetic relationships among taxa representing the 7 currently classified metastrongyloid families or to elucidate the sister group to the Metastrongyloidea. In this study, we used near-complete SSU ribosomal DNA (rDNA) sequences and partial sequences from the nuclear large-subunit ribosomal RNA (LSU rRNA) gene to test the hypothesis of metastrongyloid monophyly and to reconstruct the phylogeny of taxa representing each of the 7 families.

\section{MATERIALS AND METHODS}

\section{Specimens}

One, or more, species from each of the 7 currently accepted metastrongyloid families (Anderson, 1978) was used for molecular study and archived as voucher specimens. Many of the specimens were collected from various mammalian hosts in California, with additional specimens provided by colleagues (Table I). Adult nematodes were identified to genus level using the keys of Anderson (1978); species were identified by comparing with published descriptions. After measurements of specimens were obtained, the midbody was removed for DNA extraction, and the anterior and posterior ends of each worm were prepared as glycerine-alcohol voucher specimens. These vouchers have been de- 
TABLE I. Taxa used in this study.

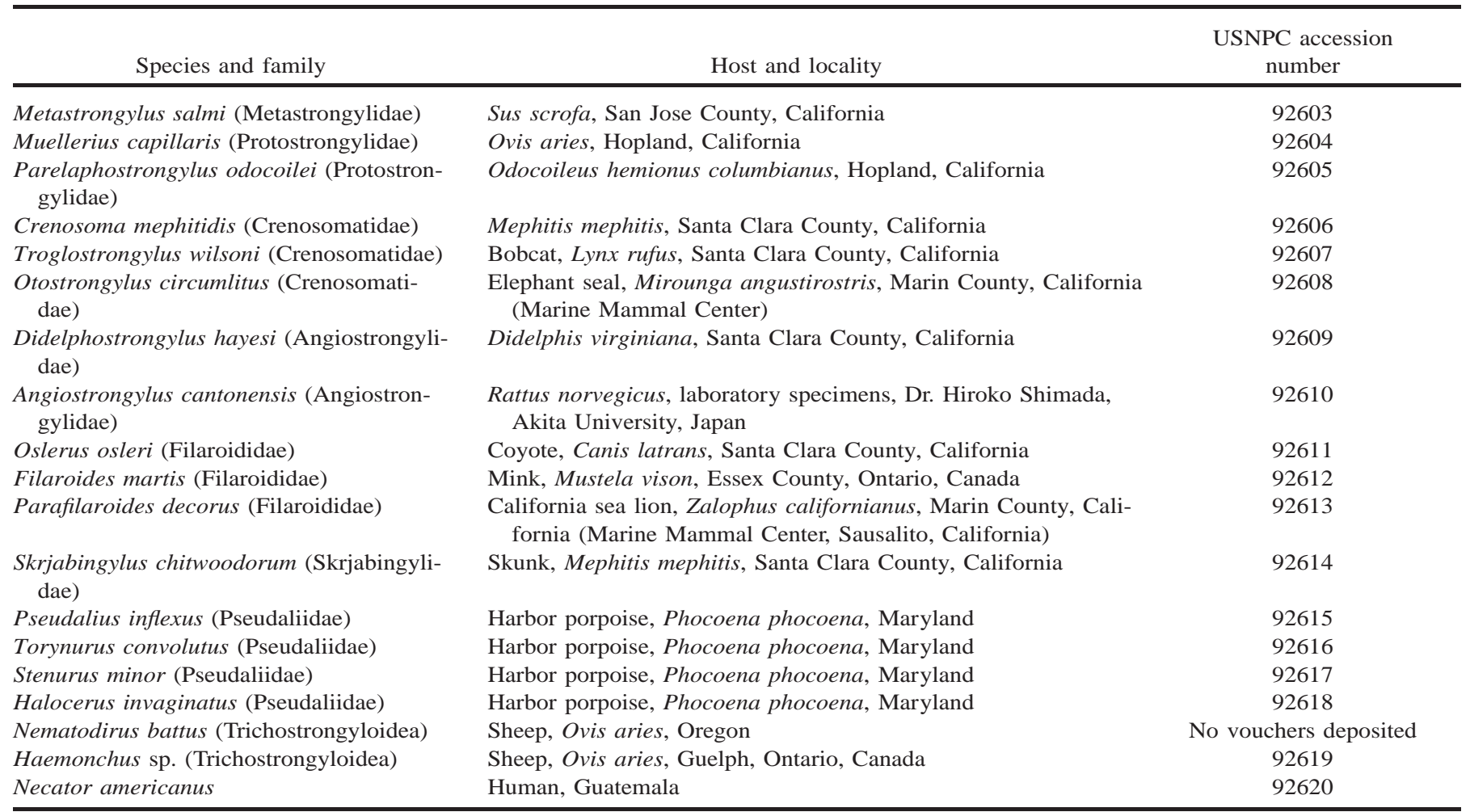

posited in the U.S. National Parasite Collection, Beltsville, Maryland (accession numbers shown in Table I).

\section{DNA extraction and polymerase chain reaction}

After overnight digestion of nematode tissues with proteinase $\mathrm{K}$, DNA was extracted using the DNAzol kit (Molecular Research Center, Cincinnati, Ohio). Three regions of nuclear rDNA were amplified by polymerase chain reaction (PCR). Approximately $1,750 \mathrm{bp}$ of the $18 \mathrm{~S}$ or SSU rDNA was amplified in 2 overlapping pieces using primers 47 forward (5'-CCCGATTGATTCTGTCGGC) and 112 reverse (5'GGCTGCTGGCACCAGACTTGC) with the overlapping primers 135 forward (5'-CGGAGAGGGAGCCTGAGAAACGGC) and 136 reverse (5'-TGATCCTTCTGCAGGTTCACCTAC). A 950-bp fragment of the $5^{\prime}$ end of $28 \mathrm{~S}$ or LSU rDNA containing the D2 and D3 domains was amplified using primers 391 forward (5'-AGCGGAGGAAAAGAAACTAA) and 501 reverse (5'-TCGGAAGGAACCAGCTACTA), as described in Nadler et al. (2000). The third amplified region consisted of $850-900$ bp of the $3^{\prime}$ end of the LSU rDNA. This region was amplified using primers 537 forward (5'-GATCCGTAACTTCGGGAAAAGGAT) and 531 reverse (5'-CTTCGCAATGATAGGAAGAGCC).

PCR reactions of $25 \mu \mathrm{l}$ consisted of $0.5 \mu \mathrm{M}$ of each primer, $200 \mu \mathrm{M}$ deoxynucleoside triphosphates, and an $\mathrm{MgCl}_{2}$ concentration of $2 \mathrm{mM}$. Proofreading polymerase (Finnzymes DyNAzyme EXT, MJ Research, Watertown, Massachusetts) was used for amplification. PCR cycling parameters for the rDNA reactions included denaturation at $94 \mathrm{C}$ for 3 min, followed by 35 cycles of $94 \mathrm{C}$ for $30 \mathrm{sec}, 58$ or $60 \mathrm{C}$ for $30 \mathrm{sec}$, and $72 \mathrm{C}$ for $1 \mathrm{~min}$, followed by a postamplification extension of $72 \mathrm{C}$ for $7 \mathrm{~min}$. The LSU rDNA was amplified using an annealing temperature of $54 \mathrm{C}$ ( $5^{\prime}$ end) or $56 \mathrm{C}$ ( $3^{\prime}$ end).

Amplified PCR products were prepared for direct sequencing using enzymatic treatment with exonuclease I and shrimp alkaline phosphatase (PCR Product pre-sequencing kit, USB Corporation, Cleveland, Ohio). Sequencing reactions were performed using ABI BigDye v3.0 (Applied Biosystems, Foster City, California) terminator sequencing chemistry, and reaction products were separated and detected using an ABI 3100 capillary DNA sequencer. Sequences from the LSU 5' end for Stenurus minor and Halocerus invaginatus could not be completed by direct sequencing; this lack of an unambiguous sequence signal appeared to result from slippage of the sequencing polymerase.

PCR products were sequenced for both strands and the contigs assembled using Sequencher version 3.0 (Gene Codes, Ann Arbor, Michigan). Completed sequences were first aligned using Clustal $\mathrm{X}$ version $1.53 \mathrm{~b}$ (Thompson et al., 1997) and subsequently edited manually to improve inferences of positional homology. Phylogenetic analysis of DNA sequences was performed using PAUP* 4.0b10 (Swofford, 1998). Sequence alignments were analyzed by maximum parsimony using branch-and-bound or heuristic search methods. Trees were inferred for each rRNA gene region individually, and a final combined analysis was conducted in which these sequence data were included in a single matrix. Alignments were truncated for small regions of their $5^{\prime}$ and $3^{\prime}$ ends so that all analyzed sequences were represented by complete data for all taxa. All aligned data were included for each region in 1 set of analyses. However, both the SSU and LSU alignments contained regions that were judged ambiguous with respect to positional homology inference, and these regions were excluded from a second set of analyses to assess the impact of these sites on the phylogenies. These alignment-ambiguous regions included positions 704-707 in the SSU data set; 403-423, 494-510, 524-537, 558-569, 598-627, and 780-820 in the LSU 5' data set; and 42-71, 545-562, and 632-635 in the LSU $3^{\prime}$ data set. Relative reliability of clades was assessed using 1,000 replicates of bootstrap resampling. Phylogenetic trees were viewed and printed using Treeview (Page, 1996).

\section{RESULTS}

Sequences obtained for metastrongyloids and outgroups (Nematodirus battus, Haemonchus sp., and Necator americanus) have been deposited in GenBank: accession numbers AY295804-AY295820 for SSU rDNA, AY292792-AY292807 for LSU rDNA (5' end), and AY295821-AY295837 for LSU rDNA ( $3^{\prime}$ end). Data matrices and trees have been deposited in TreeBASE (Sanderson et al., 1994). 


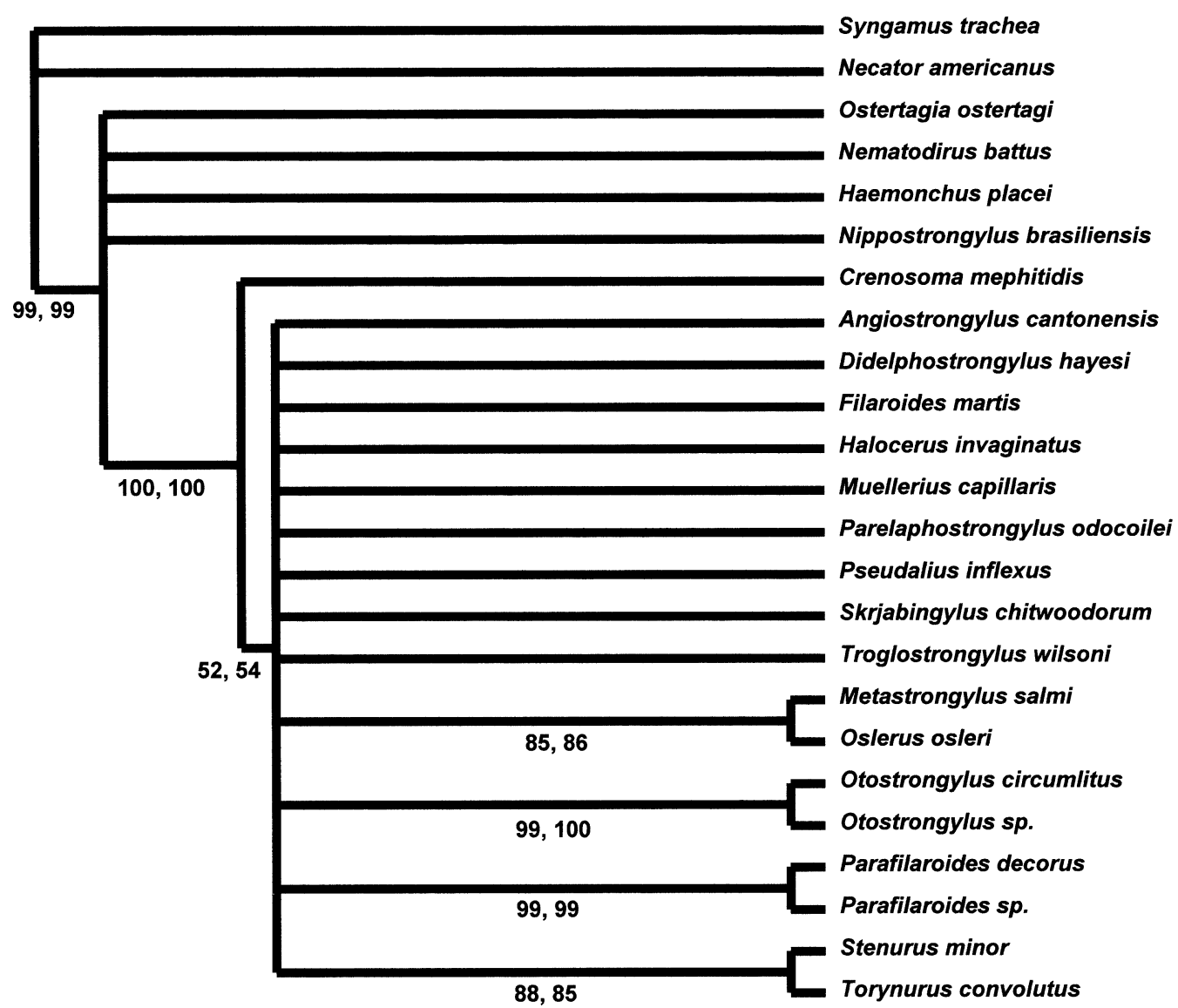

FIGURE 1. Bootstrap 50\% majority rule consensus tree (1,000 replicates) depicting phylogenetic relationships among the Metastrongyloidea inferred from SSU rDNA sequences. Bootstrap values from the full data set (first value) as well as from the analysis in which alignment ambiguous characters were excluded (second value) are shown below internal nodes.

Trichostrongyloid and metastrongyloid SSU rDNA sequences were used to test the presumed monophyly of the Metastrongyloidea, as inferred from traditional classifications. For comparative analysis, additional strongylid SSU rRNA sequences from GenBank were used. These sequences were limited to representatives of the Trichostrongyloidea (Ostertagia ostertagi, AF036598 and Nippostrongylus brasiliensis, AF036597; $N$. battus, U01230; and Haemonchus placei, L04154), 1 species in the Strongyloidea (Syngamus trachea, AF036606) and 2 metastrongyloids (Parafilaroides sp., U81590 and Otostrongylus sp., U81589). Phylogenetic analyses using SSU rDNA sequences have consistently represented the Strongylida as monophyletic (Aleshin et al., 1998; Blaxter et al., 1998; Blaxter, 2001). Use of various other outgroups such as Heterorhabditis bacteriophora (AF036593) yielded poor resolution among the Strongylida, and nonstrongylid outgroups for the Metastrongyloidea were not further explored. Furthermore, a comparative data set of LSU sequences for potential nonstrongylid outgroups was not available for analyses. Therefore, we used $S$. trachea and $N$. americanus as outgroups and included available GenBank trichostrongyloid sequences in our metastrongyloid sequences in the ingroup. In the analysis using all the aligned SSU sequence data, there were 1,649 characters of which 1,472 were constant; 101 of 177 variable characters were parsimony informative. Branch-and-bound analysis of this data set yielded 30 equally parsimonious trees with a consistency index of $61.7 \%$ and a homoplasy index of $38.3 \%$. A branch-and-bound analysis in which characters 704-707 were excluded (1,645 characters, of which 1,470 were constant; 100 of 175 variable characters were parsimony informative) yielded 60 equally parsimonious trees with a consistency index of $61.5 \%$ and a homoplasy index of $38.5 \%$. Few ingroup clades were resolved in the bootstrap consensus tree, which had an identical overall topology (Fig. 1) in analyses of both data sets (with and without character exclusion). However, the monophyly of the Metastrongyloidea received $100 \%$ support in both analyses. There was also very weak (52\% with all data, 54\% with excluded characters) support for a clade of all metastrongyloids, excluding Crenosoma mephitidis, in the bootstrap consensus tree. Within the metastrongyloids, 4 clades were resolved in the bootstrap tree, but there was no resolution among clades. These 4 resolved clades included M. salmi and O. osleri (strongly supported at $85 \%$ with all data and $86 \%$ with excluded characters), 2 Parafilaroides taxa $(P$. decorus and the Parafilaroides sp. from GenBank, supported at 99\%), 2 Otostrongylus taxa (Otostrongylus circumlitus and Otostrongylus sp. from GenBank, supported at $99 \%$ with all data and $100 \%$ with excluded characters), and 2 pseudaliids (Torynurus convolutus and S. minor, supported at $88 \%$ with all data and $85 \%$ with excluded characters). 
Phylogenetic analysis of 16 LSU rDNA sequences from the 5 '-end region in which all aligned sites were included was based on 1,005 characters of which 630 were constant. Of the 375 variable characters, 235 were parsimony informative. A Haemonchus sp. sequence and $N$. battus were used as outgroups for this analysis. Phylogenetic analysis yielded 4 equally parsimonious trees of 921 steps, with a consistency index of $59.2 \%$ and a homoplasy index of $40.8 \%$. Bootstrap support (Fig. 2a) was moderate $(64 \%)$ for a clade containing all the metastrongyloids excluding the 3 crenosomatid taxa and S. chitwoodorum. Within the larger metastrongyloid clade, there was moderate bootstrap support $(69 \%)$ for a clade containing the 2 representative pseudaliid sequences and $P$. decorus. Likewise, pseudaliid monophyly received moderate bootstrap support (71\%). Other clades within the larger metastrongyloid group were not supported as assessed by bootstrap resampling (Fig. 2a). For the metastrongyloid taxa that were excluded from the main clade, the only group recovered in the bootstrap consensus tree (at 62\%) represented a sister group relationship between $O$. circumlitus and $S$. chitwoodorum.

A second phylogenetic analysis of sixteen $5^{\prime}$-end LSU rDNA sequences (135 alignment ambiguous characters excluded) was based on 870 characters of which 165 were parsimony informative. Haemonchus sp. and $N$. battus were again used as outgroups, and the parsimony analysis yielded 2 trees of 583 steps, with a consistency index of $59.3 \%$ and a homoplasy index of $40.7 \%$. Both trees excluded the crenosomatids and S. chitwoodorum from a larger clade containing the other metastrongyloid taxa. Differences between the 2 equally parsimonious trees were limited to the clade containing Oslerus osleri, M. salmi, 2 angiostrongylid sequences, and 2 protostrongylid sequences. There was moderate to weak bootstrap support for some ingroup clades (Fig. 2b), including a clade consisting of all metastrongyloids except the crenosomatids plus $S$. chitwoodorum (79\%), 1 consisting of the pseudaliid sequences plus $P$. decorus $(62 \%)$, and another containing the 2 pseudaliid sequences $(73 \%)$.

A phylogenetic analysis of the $3^{\prime}$ end of the LSU rDNA in which all characters were included was based on 951 characters. Of the 147 variable characters, 62 were parsimony informative. Branch-and-bound analysis of this data set yielded 3 equally parsimonious trees having a consistency index of $73.7 \%$ and a homoplasy index of $26.3 \%$. Bootstrap support (Fig. 3) was weak $(51 \%)$ for a clade containing all the metastrongyloids except $O$. osleri. There was also weak support for a clade containing $M$. capillaris and the 3 included pseudaliid sequences. Other than the $100 \%$ support for the monophyly of the metastrongyloid sequences, the only strong bootstrap support from these 3 '-end LSU data was for the clade containing $S$. minor and T. convolutus (Fig. 3).

Phylogenetic analysis of the $3^{\prime}$ end of the LSU rDNA in which characters were excluded, was based on 899 characters; 53 of 107 variable characters were parsimony informative. Branch-and-bound analysis of this data set yielded 102 equally parsimonious trees of 190 steps, with a consistency index of $68.4 \%$ and a homoplasy index of $31.6 \%$ (trees not shown). For these data, the monophyly of the metastrongyloids (100\%) and, within this group, the monophyly of a clade of 3 pseudaliid sequences $(64 \%)$ were reliably supported by bootstrap resam- pling. The only other well-supported clade contained S. minor and $T$. convolutus $(99 \%)$.

The aligned sequences from both SSU and LSU rRNA genes (3 regions) were combined into a single data matrix and first analyzed with inclusion of all the characters. Of 3,605 characters, 657 were variable, and of these, 357 were parsimony informative. Phylogenetic analysis yielded 2 equally parsimonious trees of 1,436 steps, a consistency index of $61.7 \%$, and a homoplasy index of $38.3 \%$ (Fig. 4).

Using an alignment with characters excluded as described previously, the data matrix of 3 combined rDNA regions comprised 3,414 characters, (of which 278 were parsimony informative). Branch-and-bound parsimony analysis yielded 3 trees with a length of 1,034 steps, a consistency index of $61.5 \%$, and a homoplasy index of $38.5 \%$. The 3 most parsimonious trees differed with respect to the sister group relationships of the 3 crenosomatid taxa and $S$. chitwoodorum. These taxa were excluded from a clade containing the other metastrongyloid taxa. The larger metastrongyloid clade contained some resolved subclades, including 1 with the pseudaliid taxa, $P$. decorus, and $F$. martis, and others such as the clade containing M. salmi and $O$. osleri. The only difference between trees in the 2 analyses was the lack of an A. cantonensis-D. hayesi sister group relationship in the analysis in which all data were included.

Bootstrap resampling from both analyses (all data vs. exclusion of alignment ambiguous characters) yielded an identical $50 \%$ majority rule consensus tree. However, the level of bootstrap support varied in these trees. For both data sets, there was strong support for the monophyly of the Metastrongyloidea (Fig. 4) and reliable support (71 and 79\%) for a clade containing all the metastrongyloids except the crenosomatids and $S$. chitwoodorum. Within the larger clade containing the noncrenosomatid metastrongyloids, there was weak bootstrap support for monophyly of the 2 protostrongylids (51 and 62\%), similar (61 and 63\%) support for a clade containing $O$. osleri and $M$. salmi, and strong support (93 and $90 \%$ ) for the monophyly of the 2 pseudaliids (T. convolutus and Pseudalius inflexus). There was also support (77\% in both analyses) for a clade representing $P$. decorus as the sister taxon to the Pseudaliidae. Monophyly of the 2 representatives of the Angiostrongylidae, although recovered in the most parsimonious trees, was not supported by bootstrap resampling. In addition, there was no support for the monophyly of the sampled crenosomatids, and the relationship of $S$. chitwoodorum to the crenosomatid taxa was unresolved in the bootstrap consensus tree.

\section{DISCUSSION}

Our choice of rRNA gene sequences was based on the conserved nature of this nuclear DNA locus and its potential use for providing many informative characters for comparative analysis with other nematode taxa. In preliminary studies examining the use of other loci, sequences from regions coding for the mitochondrial genes cytochrome- $c$ oxidase subunit I and $12 \mathrm{~S}$ rRNA yielded poorly resolved phylogenetic hypotheses for a sample of Metastrongyloidea (data not shown). The nuclear rRNA sequences used in this study did not robustly resolve all metastrongyloid relationships. However, there was strong support both for the monophyly of the Metastrongyloidea and, within this group, the monophyly of a clade that excluded cren- 

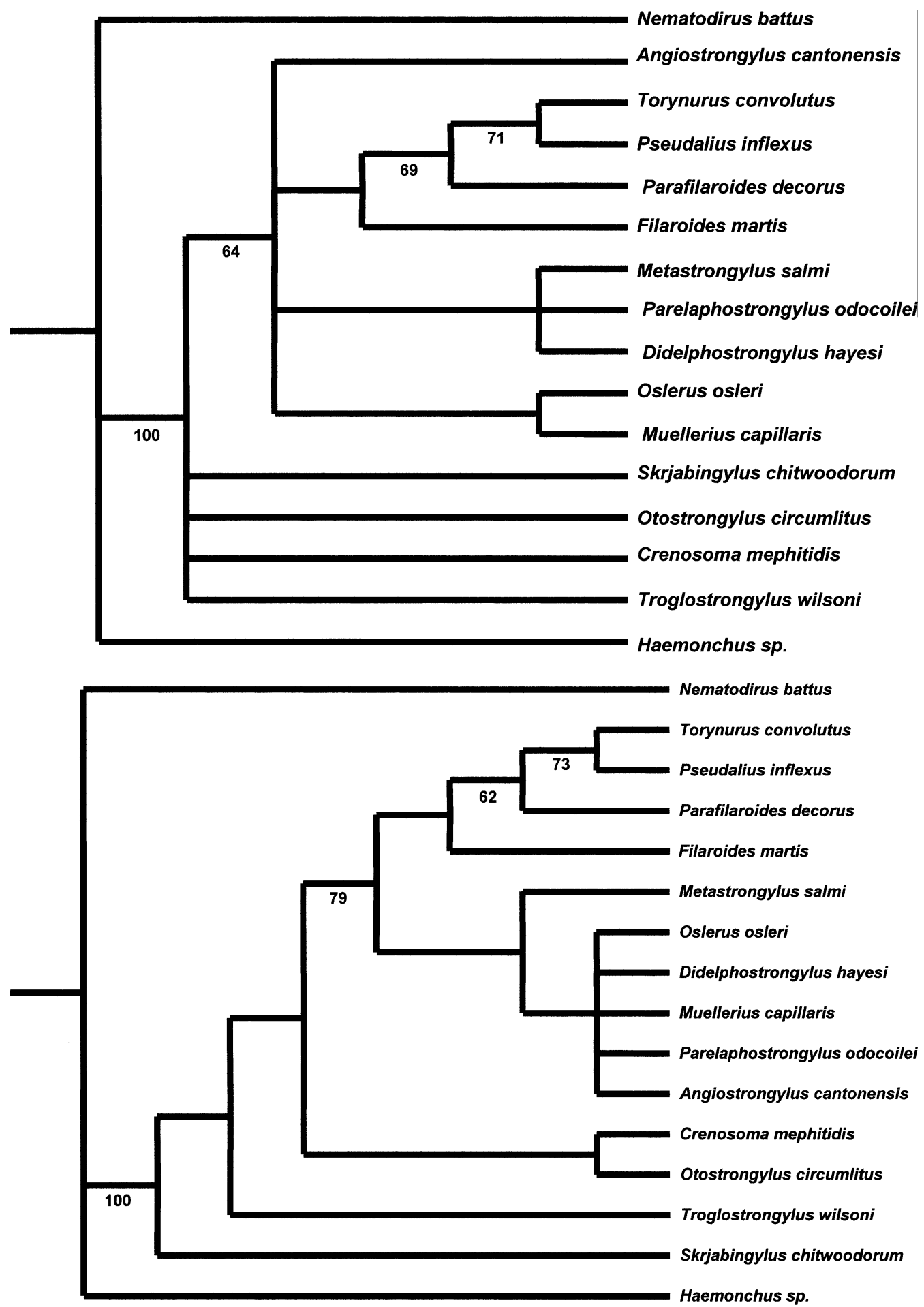

FIGURE 2. (a) Strict consensus of 4 equally parsimonious trees depicting phylogenetic relationships among the Metastrongyloidea as inferred from LSU rDNA 5'-end sequences using the full alignment. Bootstrap values (from 1,000 replicates) for clades exceeding 50\% support are mapped onto the tree. (b) Strict consensus of 2 equally parsimonious trees depicting phylogenetic relationships among the Metastrongyloidea as inferred from LSU rDNA 5 '-end sequences in which alignment ambiguous characters were excluded from the analysis. Bootstrap values (from 1,000 replicates) for clades exceeding 50\% support are mapped onto the tree. 


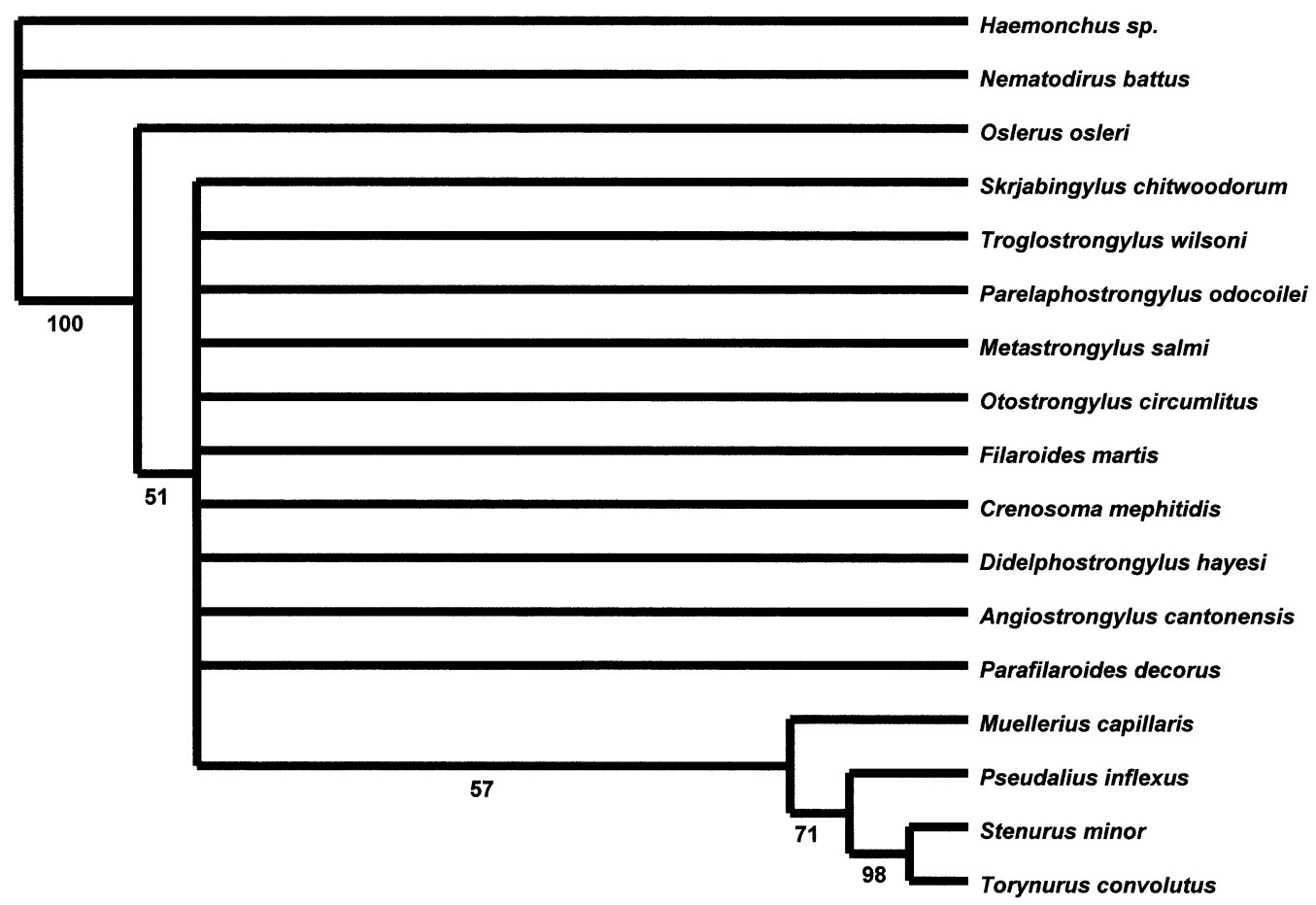

FIGURE 3. Bootstrap 50\% majority rule consensus tree depicting phylogenetic relationships among the Metastrongyloidea as inferred from LSU rDNA 3'-end sequences using the full alignment. Bootstrap values (from 1,000 replicates) for clades exceeding 50\% support are shown below internal nodes.

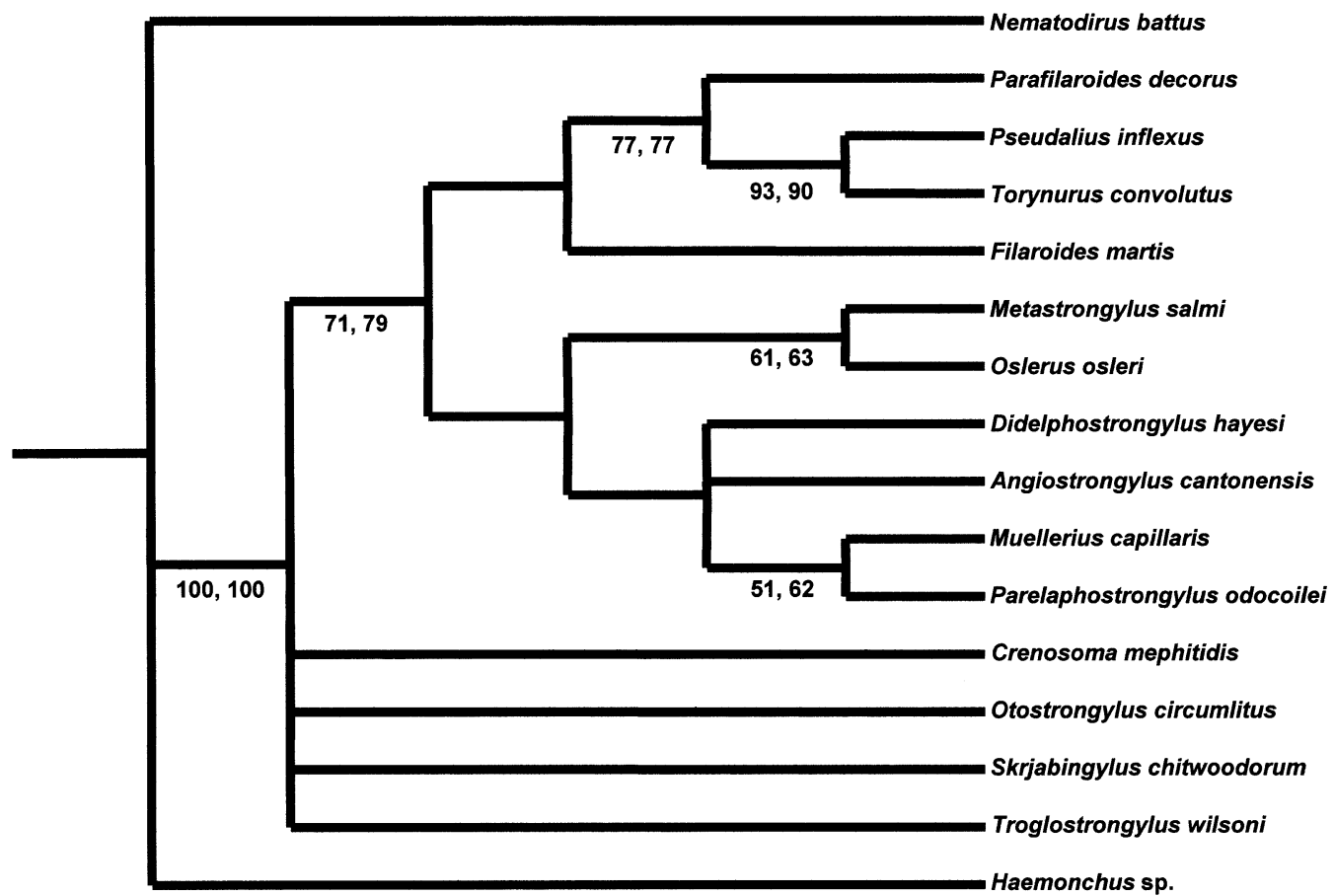

FIGURE 4. Strict consensus of 2 equally parsimonious trees based on combined analysis of all rDNA data (SSU rDNA and 2 regions of the LSU rDNA) without exclusion of alignment ambiguous characters. Bootstrap values for clades exceeding 50\% support are mapped onto the tree. Bootstrap values from a second analysis that excluded alignment ambiguous characters are listed second. 
osomatids and the single skrjabingylid representative. Within this clade, other patterns inconsistent with current views on metastrongyloid evolution and taxonomy were also evident. This pattern, as well as the support for various other clades described previously, was not affected by the exclusion of characters that appear to be alignment ambiguous in the combined sequence analysis.

The Metastrongyloidea have traditionally been grouped together on the basis of certain shared similarities that have not been established as synapomorphic characters. Named as a family before being elevated to superfamily rank by Lane (1917) without a formal definition of the taxon, metastrongyloids were originally distinguished from other strongylids on the basis of a "simple mouth" and a "bursa with true rays" (Leiper, 1909). Leiper further distinguished currently accepted trichostrongyloids from metastrongyloids by the presence of a short vagina, divergent uteri, and musculature differentiated into ovejectors in the former, and an elongate vagina, uteri lying close together, and simple musculature rather than ovejectors in the latter. However, ovejectors are present in the Metastrongyloidea, and more recent metastrongyloid classifications have not yet incorporated various differences in their morphology across various families. The ovejectors typical of trichostrongyloids have been described as "eliminated" in metastrongyloids and replaced with a poorly muscularized ovejectoral apparatus (Dougherty, 1949b). However, Dougherty (1949a) described the ovejectors of Skrjabingylus, Crenosoma, and the trichostrongyloid, Dictyocaulus, as being more typical of the trichostrongyloid ovejector. This description is interesting in light of molecular phylogenetic results depicting the unresolved group of crenosomatids and Skrjabingylus spp. as a grade distinct from the other metastrongyloid nematodes that were included in our analysis. Original descriptions of the other included crenosomatids, Otostrongylus circumlitus (de Bruyn, 1933), and Troglostrongylus wilsoni (Sarmiento and Stough, 1956), which show ovejectors similar to the "trichostrongyloid type" described by Dougherty. To develop a more comprehensive understanding of ovejector character evolution based on the phylogenetic hypothesis, ovejector morphology of other metastrongyloids must first be studied in much greater detail.

Current taxonomic superfamilial characters for the Metastrongyloidea include a reduced bursa relative to other strongylid nematodes, the generally heteroxenous life cycles, and the location of adults in extraintestinal predilection sites, primarily the respiratory system (Anderson, 1978; Kontrimavichus et al., 1985). These individual characteristics are not exclusive to the Metastrongyloidea, and their combination cannot be considered a synapomorphy. Despite the presence of certain of these features in other strongylid nematodes, the available $18 \mathrm{~S}$ sequences from superfamilies of all the Strongylida (except the Diaphanocephaloidea) indicate that the Metastrongyloidea are monophyletic; morphological data have not yet been analyzed phylogenetically to test metastrongyloid monophyly. Although combined analyses of these rDNA sequences do not resolve all lungworm relationships, they provide novel insights into certain aspects of the evolutionary history of this group. For example, within the well-supported (79\% of bootstrap replicates) clade that excluded Skrjabingylus chitwoodorum and all the crenosomatids, unexpected findings included the support for a Metastrongylus-Oslerus sister group relationship, polyphyly of the
Filaroididae, and bootstrap support (77\%) for a clade containing the filaroidid, $P$. decorus, with members of the Pseudaliidae. The Filaroididae Schulz, 1951 have generally been defined as those metastrongyloid nematodes in which the bursa is rudimentary or lacking (Seneviratna, 1959; Anderson, 1978; Kontrimavichus and Delyamure, 1979). It has been suggested that the bursa became atrophied or completely disappeared during the evolutionary history of filaroidid nematodes and that caudal papillae in some species resemble remnants of ventral or lateral rays (Anderson, 1982; Durette-Desset et al., 1994). Our phylogenetic analyses do not support a common ancestry for those species in which a bursa is absent. Representative sequences from $O$. osleri, Filaroides martis, and P. decorus were polyphyletic, indicating that the loss or reduction of the bursa occurred more than once. The caudal end of male filaroidids often has several papillae, and their size and arrangement have been inconsistently described in many species. Detailed redescriptions of the tails from a diversity of species may well reveal patterns more consistent with their sister group relationships with other taxa.

The clade containing Metastrongylus salmi and O. osleri was unexpected because these 2 species differ considerably in their morphology and life cycles. The bursa of Metastrongylus species is large and well developed with long spicules, and the cephalic region has 3 large, well-defined "lips." Metastrongylus species are the only metastrongyloids known to use earthworms as intermediate hosts, whereas the life cycle of $O$. osleri is homoxenous. In addition, $O$. osleri lacks a bursa, large lips, and long spicules, having instead shorter, thicker spicules. Although more metastrongyloids must be sampled to understand patterns of character evolution in the group, this result suggests that closely related taxa may have a history of marked character change. The taxonomic validity of Oslerus has been widely debated, and many authors have synonymized it with Filaroides. However, Anderson (1978) supported the validity of $\mathrm{Os}$ lerus by distinguishing the subterminal or terminal position of the female anus and vulva in Oslerus spp. from Filaroides spp., in which the anus and vulva are more distant from the caudal extremity. Surprisingly, the morphology of $O$. osleri has never been described in detail. As with other filaroidid species, detailed study and redescription may reveal many new characters that may be informative for phylogenetic analysis.

The well-supported clade grouping $P$. decorus with the monophyletic Pseudaliidae was also unexpected because Parafilaroides spp. have usually been considered as members of the Filaroididae, typically a "subgenus" of Filaroides (Anderson, 1978; Gosselin and Measures, 1997) on the basis of the absence of a bursa in this group. Parafilaroides spp. were originally defined as similar to Filaroides spp. but distinct in having "papillary rays" not clearly evident (and thus "degenerate") and in having smaller spicules than those of Filaroides spp. (Dougherty, 1946). More recent descriptions of Parafilaroides spp., including $P$. gymnurus, have illustrated the difficulty in understanding the morphology of these worms because of their delicate nature and indistinct morphological features (Gosselin and Measures, 1997). Interestingly, P. gymnurus was first described as a Pseudalius species, to include species with an indistinct bursa (Railliet, 1899) in this family. Morphologically, the affinities of Parafilaroides species to members of the Pseudaliidae are not apparent. Most pseudaliids, such as Pseudalius 
spp. and Stenurus spp., have distinct structures at their caudal ends (e.g., Arnold and Gaskin, 1975). However, others, like $H$. invaginatus, have a greatly reduced bursa that is virtually absent (data not shown; Dougherty, 1944). Our results support the hypothesis that $P$. decorus is more closely related to the Pseudaliidae than to other Filaroididae and that the Filaroididae are polyphyletic, indicating that the loss of the bursa in these taxa occurred independently during evolutionary history.

The Pseudaliidae, as represented by 2 species ( $P$. inflexus and T. convolutus) in the combined data set, were monophyletic. Unfortunately, sequences from the $5^{\prime}$ end of the LSU gene of $S$. minor and $H$. invaginatus could not be completed and, therefore, these additional pseudaliids were not included in the combined analysis. Nevertheless, based on the combined data set, the included Pseudaliidae were nested in a clade containing other metastrongyloids. This finding contradicts hypotheses describing the pseudaliids as "ancestors" of the other Metastrongyloidea (Skrjabin, 1941). Skrjabin postulated the evolution of the metastrongyloids with a more complex bursa from pseudaliid ancestors and hypothesized that Skrjabingylus was a "side branch" from the Pseudaliidae (Skrjabin, 1941, 1942). Contrasting views, including those of Schulz (1951) and Dougherty (1949b), did not support a pseudaliid as ancestral to the other metastrongyloids. Dougherty (1949b) described the pseudaliids as branching from a filaroidid lineage. The ancestor of both groups would thus have had the typical metastrongyloid bursa, which was changed (Pseudaliidae) or lost (Filaroididae) in these 2 descendant lineages. Our results do not support the overall phylogenetic hypotheses of Dougherty (1949b) but are consistent with an evolutionary scenario wherein there were multiple modifications of an ancestral type of metastrongyloid bursa in genera representing the "Filaroididae" (a nonmonophyletic assemblage) and Pseudaliidae.

Dougherty (1949b) emphasized the coevolution of various metastrongyloid lineages with their distinct host groups. This emphasis was also shared by Delyamure (1955), who hypothesized a close phylogenetic affinity between the Skrjabingylidae and Pseudaliidae. This notion was based on hypotheses of a close evolutionary relationship between their mustelid and cetacean hosts; on the presence of pseudaliids in the circulatory system, frontal sinuses, and auditory organs; and the similar location of skrjabingylids in the frontal sinuses of mustelids. However, more recent phylogenetic data for cetaceans indicate a closer relationship of this group to ungulates rather than to the carnivores (Berta and Sumich, 1999). In addition, different coevolutionary hypotheses that have been described were based on generalizations for entire families. Not only is the a priori assumption of host-parasite coevolution unwarranted but such patterns would be difficult to support because certain lungworm families in this study were found to be poly- or paraphyletic. Furthermore, many species from different families parasitize the same host groups, thus further complicating coevolutionary patterns.

Inclusion of other metastrongyloid and trichostrongyloid taxa will be necessary to further test and refine these evolutionary hypotheses, including those resulting from future molecular and morphological phylogenetic analyses. Although we were able to include a broad range of taxa from each of the metastrongyloid families, it remains untested whether each of the 7 families is monophyletic and unusual forms currently classified in families that include dissimilar species must also be sampled. For example, a wide morphological diversity exists within the families Protostrongylidae and Angiostrongylidae, which was well illustrated from a phylogenetic analysis of the Protostrongylidae using morphological characters (Carreno and Hoberg, 1999). Comparable data for the trichostrongyloid lungworms of the genus Dictyocaulus would also be valuable, and there are unusual pseudaliid genera such as Skrjabinalius from cetaceans and Stenuroides herpestis from the mongoose that have been classified in the Pseudaliidae. Representative taxa from all these examples should be included in future analyses to provide a more comprehensive representation of metastrongyloid diversity. Robust identification of sister groups, i.e., for the Pseudaliidae and the Skrjabingylidae, may help identify interesting patterns of evolutionary transition such as colonization of marine mammalian hosts (pseudaliids, Otostrongylus circumlitus, and Parafilaroides spp.) or the nature of tissue colonization of predilection sites away from the respiratory tract (Skrjabingylus spp.).

\section{ACKNOWLEDGMENTS}

We thank Ashleigh Smythe for assistance with necropsy work. We are also grateful to the following colleagues who provided either specimens or host tissues for this study: Patricia Arseneault and Janet Neilson, Erie Wildlife Rescue, Ontario, Canada; Murray Dailey, The Marine Mammal Center, Sausalito, California; Robert M. Timm and Robert J. Keiffer, University of California Hopland Research and Extension Center, Hopland, California; Susan Knowles, Maryland Department of Natural Resources, Maryland; Kelly Robertson, National Marine Fisheries Service, La Jolla, California; Don Rocha, Santa Clara County, California; Pamela Swift, California Department of Fish and Game, California; Hiroko Shimada, Akita University, Japan; Noor Tietze, Santa Clara Vector Control District, California, and Ben Sacks, University of California-Davis, Davis, California. Collection of nematodes from marine hosts was facilitated and permitted by the National Marine Fisheries Service. We are grateful to Eric Hoberg, U.S. National Parasite Collection, Beltsville, Maryland, for providing specimens of $N$. battus and to personnel at the USNPC for archiving the vouchers from this study. This research was supported by a postdoctoral fellowship to R.A.C. from the Natural Sciences and Engineering Research Council of Canada and by a National Science Foundation grant (DEB-0234520) to R.A.C. and S.A.N.

\section{LITERATURE CITED}

Aleshin, V. V., O. S. Kedrova, I. A. Milyutina, N. S. VladychenSKAYA, AND N. B. PETROV. 1998. Secondary structure of some elements of $18 \mathrm{~S}$ rRNA suggests that strongylid and a part of rhabditid nematodes are monophyletic. FEBS Letters 429: 4-8.

ANDERSON, R. C. 1978. Keys to the genera of the superfamily Metastrongyloidea, no. 5. In CIH keys to the nematode parasites of vertebrates, R. C. Anderson, A. G. Chabaud, and S. Willmott (eds.). Commonwealth Agricultural Bureaux, Farnham Royal, U.K., p. 140 .

- 1982. Host-parasite relations and evolution of the Metastrongyloidea (Nematoda). Deuxieme symposium sur la specificite parasitaire des parasites de vertebres. 13-17 avril 1981. Memoires du Muséum National d'Histoire Naturelle, Serie A, Zoologie 123: 129-133.

. 2000. Nematode parasites of vertebrates: Their development and transmission, 2nd ed. CAB International, Wallingford, U.K., $650 \mathrm{p}$.

ARnOLD, P. W., AND D. E. GASKIN. 1975. Lungworms (Metastrongyloidea: Pseudaliidae) of harbor porpoise Phocoena phocoena (L. 1758). Canadian Journal of Zoology 53: 713-735.

Baker, D. G., L. F. CoOK, E. M. Johnson, AND N. LAMBerski. 1995 Prevalence, acquisition, and treatment of Didelphostrongylus hayesi (Nematoda: Metastrongyloidea) infection in opossums (Didel- 
phis virginiana). Journal of Zoo and Wildlife Medicine 26: 403408.

Berta, A., ANd J. L. Sumich. 1999. Marine mammals: Evolutionary biology. Academic Press, San Diego, California, 494 p.

BlaXter, M. L. 2001. Molecular analysis of nematode evolution. In Parasitic nematodes: Molecular biology, biochemistry, and immunology, M. W. Kennedy and W. Harnett (eds.). CABI International, New York, p. 1-24.

—, P. De Ley, J. R. Garey, L. X. Liu, P. Scheldeman, A. Vierstraete, J. R. Vanfleteren, L. Y. Mackey, M. Dorris, L. M. Frisse, J. T. VIDA, AND W. K. Thomas. 1998. A molecular evolutionary framework for the phylum Nematoda. Nature 392: 71-75.

Bolt, G., J. Monrad, J. Koch, and A. L. Jensen. 1994. Canine angiostrongylosis: A review. The Veterinary Record 135: 447-452.

CARreno, R. A., AND E. P. Hoberg. 1999. Evolutionary relationships among the Protostrongylidae (Nematoda: Metastrongyloidea) as inferred from morphological characters, with consideration of parasite-host coevolution. Journal of Parasitology 85: 638-648.

Chilton, N. B., R. B. Gasser, And I. Beveridge. 1997. Phylogenetic relationships of Australian strongyloid nematodes inferred from ribosomal DNA sequence data. International Journal for Parasitology 27: 1481-1494.

DaILEY, M. D. 1970. The transmission of Parafilaroides decorus (Nematoda: Metastrongyloidea) in the California Sea Lion (Zalophus californianus). Proceedings of the Helminthological Society of Washington 37: 215-222.

De BruYn, W. 1933. Beiträge zur Kenntnis von Strongylus circumlitus Railliet aus den Lungen des Seehundes: Die neue Gattung Otostrongylus. Zoologischer Anzeiger 103: 142-153.

Delyamure, S. L. 1955. Gel'mintofauna morskikh mlekopitayushchikh $\mathrm{v}$ svete ikh ekologii I filogenii. [Helminthofauna of marine mammals.] K. I. Skrjabin (ed.). Izdatel'stvo Akademii Nauk SSSR, Moscow, 1955. [Translated from Russian, Israel Program for Scientific Translations, Jerusalem, Israel, 1968, 521 p.]

Dougherty, E. C. 1944. The lungworms (Nematoda: Pseudaliidae) of the Odontoceti. Part I. Parasitology 36: 80-94.

. 1946. The genus Aeleurostrongylus Cameron, 1927 (Nematoda: Metastrongylidae), and its relatives; with descriptions of Parafilaroides, gen. nov., and Angiostrongylus gubernaculatus, sp. nov. Proceedings of the Helminthological Society of Washington 13: $16-26$.

-1949a. A list of the trichostrongylid lungworms (Phylum Nematoda) and a key to the six genera. Parasitology 39: 218-221.

- 1949b. The phylogeny of the nematode family Metastrongylidae Leiper (1909): A correlation of host and symbiote evolution. Parasitology 39: 222-234.

Durette-Desset, M. C., I. Beveridge, and D. M. Spratt. 1994. The origins and evolutionary expansion of the Strongylida (Nematoda). International Journal for Parasitology 24: 1139-1165.

- J. P. Hugot, P. Darlu, and A. G. Chabaud. 1999. A cladistic analysis of the Trichostrongyloidea (Nematoda). International Journal for Parasitology 29: 1065-1086.

Gosselin, J.- F., AND L. N. MeAsures. 1997. Redescription of Filaroides (Parafilaroides) gymnurus (Railliet, 1899) (Nematoda: Metastrongyloidea), with comments on other species in pinnipeds. Canadian Journal of Zoology 75: 359-370.

Gouy de Belloce, J. G., H. Ferte, J. Depaquit, J.- L. Justine, A. Tillier, And M. C. Durette-Desset. 2001. Phylogeny of the Trichostrongylina (Nematoda) inferred from 28S rDNA sequences. Molecular Phylogenetics and Evolution 19: 430-442.

Hoberg, E. P., AND J. R. Lichtenfels. 1994. Phylogenetic systematic analysis of the Trichostrongylidae (Nematoda), with an initial assessment of coevolution and biogeography. Journal of Parasitology 80: 976-996.

Hung, G.- C., N. B. Chilton, I. Beveridge, and R. B. Gasser. 1999. Secondary structure model for the ITS-2 precursor rRNA of strongyloid nematodes of equids: Implications for phylogenetic inference. International Journal for Parasitology 29: 1949-1964.

Kontrimavichus, V. L., and S. L. Delyamure. 1979. Osnovy Nematodologii, Tom. XXIX, Filyaroididy Domashnikh i Dikikh Zhivot- nykh. [Filaroids of domestic and wild animals. Fundamentals of nematology volume 29. Nauka Publishers, Moscow. Published for the U.S. Department of Agriculture and the National Science Foundation, Washington, D.C., by Amerind Publishing Co. Pvt. Ltd., New Delhi, India, 1985, $183 \mathrm{p}$

, - AND S. N. BoEv. 1985. Metastrongyloids of domestic and wild animals. Fundamentals of nematology, vol. 26. English Translation of Osnovy Nematodologii, Tom. XXVI, Metastrongiloidei Domashnikh I Dikikh Zhivotnykh, Nauka Publishers, Moscow. Oxonian Press Pvt. Ltd., New Delhi, India, 298 p.

LANE, C. 1917. Bunostomum kashinathi and the Ancylostomidae. Indian Journal of Medical Research 4: 414-439.

LEIPER, R. T. 1909. An account of some helminthes contained in Dr. C M. Wenyon's collection from the Sudan. Third Report of the Wellcome Research Laboratories at the Gordon Memorial College Khartoum. Bailliere, Tindall, and Cox, London, U.K., p. 187-199.

Nadler, S. A., S. D'Amelio, H.- P. Fagerholm, B. Berland, and L. PAGGi. 2000. Phylogenetic relationships among species of Contracaecum Railliet \& Henry, 1912 and Phocascaris Host, 1932 (Nematoda: Ascaridoidea) based on nuclear rDNA sequence data. Parasitology 121: 455-463.

—, AND D. S. S. HUDSPETH. 1998. Ribosomal DNA and phylogeny of the Ascaridoidea (Nemata: Secernentea): Implications for morphological evolution and classification. Molecular Phylogenetics and Evolution 10: 221-236.

PAGE, R. D. M. 1996. TREEVIEW: An application to display phylogenetic trees on personal computers. Computer Applications in the Biosciences 12: 357-358.

RaIlliEt, M. A. 1899. Sur quelques parasites rencontrés a l'autopsie d'un phoque. Comptes Rendus Hebdomadaires des Séances et Mémoires de la Société de Biologie 51: 128-130.

Sanderson, M. J., M. J. Donoghue, W. Piel, and T. Eriksson. 1994. TreeBASE: A prototype database of phylogenetic analyses and an interactive tool for browsing the phylogeny of life. American Journal of Botany 81: 183.

SARMiento, L., AND B. D. Stough. 1956. Troglostrongylus wilsoni (Stough, 1953) n.comb. (Nematoda: Metastrongylidae) from the lungs of the bobcat, Lynx rufus rufus. Journal of Parasitology 42: $45-48$.

Schulz, R. E. 1951. Phylogenesis of strongylid nematodes and reconstruction of the Metastrongyloidea. Doklady Akademii nauk SSSR 80: $293-296$.

Seneviratna, P. 1959. Studies on the family Filaroididae Schulz, 1951. Journal of Helminthology 33: 123-144.

SKRJABIN, K. I. 1941. Phylogenetic relationships of nematodes of subclass Phasmidia. Zoologicheskiai Zhurnal 20: 327-340.

. 1942. The ways of the phylogenetic evolution of nematodes of the family Pseudaliidae, parasitic of the auditory apparatus, circulatory system and respiratory organs of marine mammals. Comptes rendus (Doklady) de l'Academie des Sciences de l'URSS 37: 35 40.

, N. P. Shikhobalova, R. S. Schulz, T. I. Popova, S. N. Boev, and S. L. Delyamure. 1952. Key to the parasitic nematodes, vol. 3. Strongylata. K. I. Skrjabin (ed.). Akademia Nauk S.S.S.R. 890 p. [English translation by Israel Program for Scientific Translations, 1961.]

StOCKDALE, P. H. G. 1976. Pulmonary pathology associated with metastrongyloid infections. British Veterinary Journal 132: 595-608.

Sudhaus, W., AND D. Fitch. 2001. Comparative studies on the phylogeny and systematics of the Rhabditidae (Nematoda). Journal of Nematology 33: 1-70.

SwOFFORD, D. L. 1998. PAUP*: Phylogenetic analysis using parsimony (and other methods), version 4.0b10. Sinauer, Sunderland, Massachusetts.

Testi, F., And G. Pilleri. 1969. Verminous pulmonitis induced by Nematoda (Halocerus, Pseudaliidae) in the dolphin (Delphinus delphis L.). Investigations on Cetacea 1: 179-188.

Thompson, J. D., T. J. Gibson, F. Plewniak, F. Jeanmougin, and D. G. HigGINS. 1997. The CLUSTAL-X windows interface: Flexible strategies for multiple sequence alignment aided by quality analysis tools. Nucleic Acids Research 25: 4876-4882. 